\title{
INHIBISI KOROSI BAJA RINGAN MENGGUNAKAN BAHAN ALAMI DALAM MEDIUM ASAM KLORIDA: REVIEW
}

\author{
Yeni Stiadi*, Syukri Arief, Hermansyah Aziz, Mai Efdi, Emriadi \\ Jurusan Kimia FMIPA Universitas Andalas
}

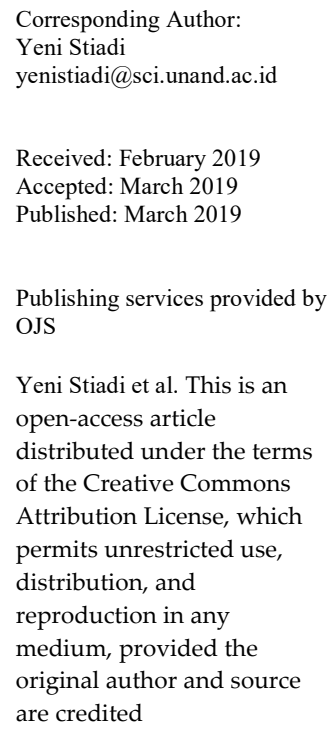

Yeni Stiadi et al. This is an open-access article distributed under the terms of the Creative Commons Attribution License, which permits unrestricted use, distribution, and reproduction in any medium, provided the original author and source are credited

\begin{abstract}
The corrosion of steel and its alloys is an important problem in industry, especially in acidic environments. Mild steel is one of the important alloys of iron which has many industrial applications because of its excellent mechanical properties, but mild steel is susceptible to corrosion. Corrosion problems need to be a concern and must be handled properly. Hydrochloric acid is widely used for pickling, cleansing, decomposition and metal etching, on the other hand also contributes to corrosion of metal surfaces. Plant extracts investigated the properties, mechanisms of adsorption and efficiency of inhibition as environmentally friendly corrosion inhibitors for various steel materials in different acidic media. The efficiency of corrosion inhibition of steel from plant extracts analyzed ranged from $72-98 \%$ and generally as a mixed-type inhibitor. Most of the inhibitors are adsorbed on the steel surface through a physisorption mechanism.
\end{abstract}

Keywords: Corrosion inhibitor; Mild steel; Weight loss; Potentiodynamic; EIS; SEM

\section{PENDAHULUAN}

Korosi biasanya didefinisikan sebagai kemerosotan logam ataupun sifatnya yang disebabkan oleh reaksi logam itu dengan lingkungannya [1]. Logam yang sudah dipadukan dengan unsur lain tidak luput dari pengaruh lingkungan. Korosi merupakan proses yang dihasilkan dari pengaruh medium pada material tertentu yang dapat menyebabkan kerusakan keseluruhan, parsial, dangkal atau struktural oleh serangan elektrokimia, kimia atau elektrolisis [2].

Baja ringan merupakan salah satu paduan besi yang penting dalam aplikasi industri dan teknik, karena sifat mekaniknya yang sangat baik ${ }^{[3]}$. Sifat mekanik baja ringan diantaranya kekuatan > $550 \mathrm{Mpa}$, modulus elastisitas 200.000 Mpa dan modulus geser 800 Mpa. Di berbagai industri, baja adalah bahan pilihan utama dalam pembuatan kapal reaksi, jaringan pipa untuk industri perminyakan, tangki penyimpanan, baterai kimia dan sebagainya, semuanya dapat terkorosi mudah dengan adanya asam. Aplikasi industri baja menarik karena beberapa sifat unik yang diperlukan untuk sebagian besar persyaratan teknik [1]. Dalam aplikasinya baja ringan memiliki biaya yang rendah dan ketersediaannya cukup tinggi.

Logam dan paduan yang bereaksi dengan media korosif membentuk senyawa yang stabil, yang dapat juga disebut sebagai produk korosi. Dalam hal ini karena hilangnya logam yang ada di permukaan dan dikatakan permukaan logam telah terkorosi [4]. Baja karbon juga memiliki peran yang besar yang cukup signifikan di dunia industri. Baja karbon banyak digunakan dalam aplikasi industri 
seperti pembersihan sisa industri dan pengolahan sumur minyak [5]. Industri minyak dan gas menggunakan berbagai bahan baja untuk membuat jalur pipa, tabung, penutup pipa maupun tabung dan konstruksi penyimpanan serta fasilitas lainnya. Walaupun kemampuan baja rendah untuk tahan terhadap serangan senyawa korosif, tetapi nilai lebih baja tetap menonjol dalam aplikasi industri [6]. Korosi kilang minyak umumnya disebabkan oleh asam kuat yang menyerang permukaan peralatan. Sedangkan bidang aplikasi industri lain yang penting adalah pengawetan asam, pembersihan industri, penguraian asam, asam yang berasal dari sumur minyak dan proses petrokimia ${ }^{[7,8]}$.

Meskipun baja ringan memiliki aplikasi yang luas, tetapi sangat rentan terhadap korosi karena ketidakstabilan termodinamika terutama pada medium asam. Kerentanan terhadap korosi disebabkan komposisi baja ringan mengandung besi yang cukup tinggi dengan nilai $\Delta G$ reaksi yang bernilai negatif. Dengan demikian studi tentang fenomena korosi baja ringan menjadi penting terutama di medium asam [9]. Besi dan baja mempunyai aplikasi industri dan struktur yang luas di lingkungan agresif berair yang bervariasi, namun tingkat korosinya pada larutan asam sering dikaitkan dengan kerugian secara ekonomi dan bahaya keamanan yang cukup besar [10]. Masalah korosi sering terjadi pada industri minyak, dimana sekitar 50\% kegagalan material di kilang minyak dan pabrik petrokimia disebabkan oleh fenomena ini. Hal ini dapat meningkatkan kerugian ekonomi, kerusakan lingkungan dan keamanan manusia [2].

Di antara larutan asam, asam klorida merupakan salah satu zat yang paling banyak digunakan. Jika baja ringan terpapar ke lingkungan korosif, maka baja rentan mengalami berbagai jenis mekanisme korosi [5,7,9]. Larutan asam banyak digunakan di industri untuk berbagai keperluan, seperti pengawet asam, pembersihan asam industri, penguraian asam dan pengasaman minyak. Karena sifat asam yang umum agresif, diperlukan berbagai metode untuk mengurangi serangan asam yang bersifat korosif terhadap bahan logam yang dikontakkan [11]. Larutan asam-asam lain seperti asam sulfat, asam fosfat, dan asan sulfida juga akan memberikan pengaruh yang besar terhadap serangan korosi pada baja ringan maupun baja karbon [1,6,8,12] .

Berbagai metode digunakan untuk mengurangi laju korosi logam dan paduan, di antaranya penggunaan inhibitor korosi yang sangat populer. Inhibitor korosi bekerja dengan melakukan adsorpsi ion atau molekul di atas permukaan logam. Inhibitor akan mengurangi laju korosi terutama dengan meningkatkan atau menurunkan reaksi anodik dan ataupun katodik, menurunkan laju difusi reaktan ke permukaan logam dan tahanan listrik permukaan logam. Untuk penggunaan inhibitor skala industri dan skala besar lain toksisitas, ketersediaan, dan ramah lingkungan menjadi sangat penting ${ }^{[4]}$.

Di antara beberapa metode pengendalian dan pencegahan korosi, penggunaan inhibitor korosi sangat populer. Penghambat korosi atau inhibitor korosi adalah zat yang jika ditambahkan dalam konsentrasi rendah pada media korosif akan menurunkan atau mencegah timbulnya reaksi antara logam dan media. Inhibitor ditambahkan ke berbagai sistem, yaitu sistem pendingin, unit kilang, bahan kimia, unit produksi minyak dan gas, ketel, dan lain sebagainya [13]. Inhibitor korosi disamping digunakan untuk menghambat laju korosi sekaligus meningkatkan dan memperpanjang umur material [6].

Pada umumnya inhibitor yang lebih dikenal dan efektif adalah senyawa organik yang mengandung heteroatom, seperti $\mathrm{O}, \mathrm{N}$ atau $\mathrm{S}$, dan beberapa ikatan yang memungkinkan terjadinya adsorpsi pada permukaan logam. Senyawa ini dapat teradsorpsi pada permukaan logam dan memblokir permukaan aktif untuk mengurangi laju korosi. Empat jenis adsorpsi dapat dilakukan oleh molekul organik pada antarmuka logam dan larutan. Keempat jenis itu meliputi (a) daya tarik elektrostatik antara molekul yang bermuatan dan logam 
bermuatan, (b) interasi elektron tanpa pasangan dalam molekul dengan logam, (c) interaksi elektron $p$ dengan logam dan (d) kombinasi dari (a) dan (c) [4,7,9,13]. Proses adsorpsi sangat bergantung pada sifat fisikokimia tertentu dari kelompok inhibitor, seperti kelompok fungsional, kerapatan elektron pada donor atom, karakter orbital $\pi$, dan struktur elektronik dari molekul [13].

Analisis kimia terhadap ekstrak kulit bawang coklat menunjukkan adanya beberapa senyawa volatil utama yaitu $3(2 \mathrm{H})$-Furanone (Gambar 1a), 2-heksil-5-metil dan sebuah basa nitrogen 5-oktadesil-pirimidin-2,4,6-trion (Gambar 1b). Senyawa ini memungkinkan untuk berperan dalam proses inhibisi korosi karena mempunyai gugus polar dengan dua amina sekunder. Kedua gugus amina ini akan terprotonasi, menghasilkan muatan positif yang akan meningkatkan aktivitas permukaan[2].

Ekstrak biji Griffonia simplicifolia (SEGS) mempunyai kandungan kimia yang dihubungkan dengan proses adsorpsi molekul inhibitor pada permukaan baja. Beberapa senyawa yang ada dalam SEGS seperti klomipramin, griffonin, amitriptilin, melatonin (Gambar 2a), fluvoksamin (Gambar 2b) dan 5hidroksitriptofan (Gambar 2c). Molekulmolekul ini kaya dengan heteroatom (oksigen dan nitrogen) dan elektron $\pi$ serta memiliki ukuran besar dan mempunyai banayk gugus yang potensial dalam proses adsorpsi. Dengan demikian SEGS dapat terserap pada permukaan baja, memblokir situs-situs aktif logam, mempunyai cakupan permukaan yang besar dan dapat mengurangi laju korosi $\log a m^{[6]}$.

Senyawa-senyawa lain yang terdapat dalam berbagai ekstrak yang mempunyai kandungan unsur $\mathrm{N}, \mathrm{S}$ dan $\mathrm{O}$ dalam kerangka strukturnya mampu berfungsi secara efektif sebagai inhibitor korosi yang sangat baik. Senyawa yang mempunyai kerangka tersebut antara lain 4-amino-3-hidrazino-5-merkapto-1,2,4-triazol

(AHMT) (Gambar 3a) [12], Lawson (Gambar 3b) dan kolin (Gambar 3c) yang terdapat dalam ekstrak daun inai dan fenugreek[13], sodium glukonat (Gambar 3d) [21], dan ervatinin (Gambar 3e) yang diisolasi dari Ervatamia coronaria [24]

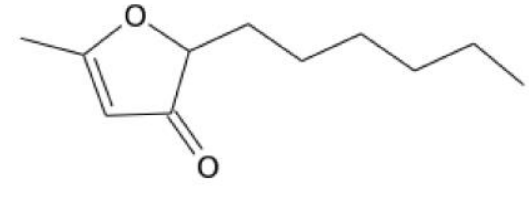

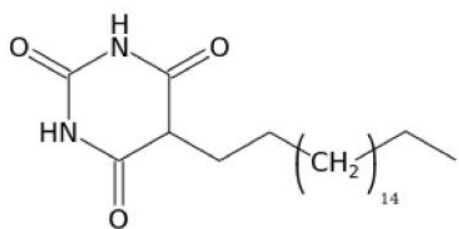

b

Gambar 1. Struktur kimia dari dua senyawa terdapat dalam ekstrak kulit bawang coklat (a) $3(2 \mathrm{H})-$ furanone, 2-heksil-5-metil, (b) 5-oktadesil-pirimidin-2,4,6-trion

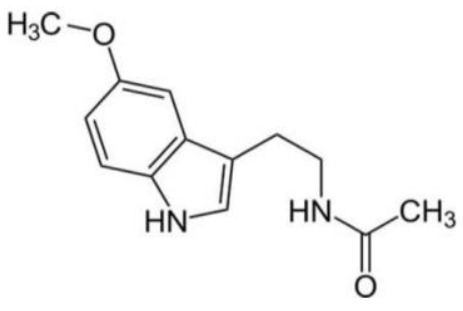<smiles>COCCCC(=NOCCN)c1ccc(C(F)(F)F)cc1</smiles>

b

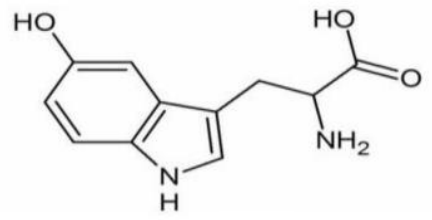

c

Gambar 2. Struktur molekul dari beberapa senyawa kimia dalam SEGS (a) melatonin, (b) fluvoksamin dan (c) hidroksitriptofan 
<smiles>[NH]n1c(NN)n[nH]c1=S</smiles>

a<smiles>N#CC(=O)C(O)C(O)C(O)[C@H](O)CO</smiles>

d<smiles>O=C1C=C(O)C(=O)c2ccccc21</smiles>

b

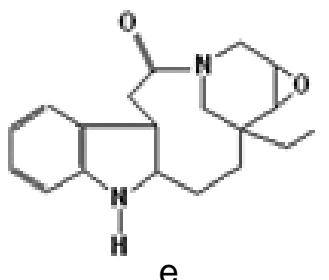<smiles>C[N+](C)(C)CCO</smiles>

C

Gambar 3. Beberapa struktur senyawa yang yang berpotensi sebagai inhibitor korosi baja ramah lingkungan (a) 4-amino-3-hidrazino-5-merkapto-1,2,4-triazol, (b) lawson, (c) kolin, (d) sodium glukonat dan (e) ervatinin.

Senyawa sintetis juga memperlihat aktivitas anti korosi yang baik, tetapi kebanyakan dari senyawa sintetis sangat beracun bagi manusia dan lingkungan [13]. Namun, sebagian besar inhibitor tradisional adalah senyawa sintetis, yang mahal dan ternyata dapat menyebabkan masalah lingkungan yang serius [11]. Penggunaan inhibitor kimia telah dibatasi karena lingkungan menjadi terancam, sehingga peraturan lingkungan harus diperketat. Inhibitor sintetik ini dapat menyebabkan kerusakan sistem organ baik reversibel (sementara) ataupun ireversibel (permanen). Kerusakan ginjal atau hati, atau mengganggu proses biokimia atau mengganggu sistem enzim di beberapa tempat di dalam tubuh merupakan contoh akibat penggunaan bahan sintetis. Toksisitas senyawa sistetis dan selama aplikasinya, menimbulkan efek berbahaya yang diketahui paling banyak diberikan oleh inhibitor korosi sintetis. Hal ini memberikan motivasi untuk penggunaan berbagai produk alami sebagai inhibitor korosi [13].

Pengembangan dan penerapan inhibitor korosi kemudian difokuskan pada zat murah dan ramah lingkungan. Ekstrak tanaman kemudian muncul sebagai inhibitor korosi yang efektif karena biaya rendah, biodegradabilitas tinggi, ketersediaan tinggi, sumber bahan yang mudah diperbaharui, dapat dierima secara ekologis dan sifat tidak beracun [6,11]. Produk tanaman bersifat organik, dan beberapa penyusunnya termasuk tanin, asam organik dan asam amino, alkaloid, dan pigmen diketahui memperlihatkan gejala inhibisi korosi. Selain itu, ekstrak tanaman didapatkan melalui proses ekstraksi dengan prosedur sederhana dan biaya rendah ${ }^{[13]}$.

Terlepas dari berbagai berbagai hal tentang inhibitor organik, inhibitor alami yang juga disebut sebagai inhibitor hijau, mendapat banyak perhatian pada tahun-tahun belakangan ini. Ekstrak tumbuhan sebagai inhibitor organik alami telah diuji selama bertahun-tahun [4]. Oleh karena itu, penggunaan inhibitor korosi untuk mencegah degradasi logam tidak dapat dielakkan. Sejumlah besar penelitian ilmiah telah dikhususkan untuk subjek inhibitor korosi untuk baja ringan di media asam [7]. Inhibitor yang paling mungkin adalah berasal dari ramuan obat dari tanaman yang telah dikenal sebelumnya. Berbagai ekstrak dari tanaman obat ataupun tumbuhan liar seperti kulit, biji dan daun akan dapat dimanfaatkan sebagai inhibitor korosi [4]. 
Studi perkembangan dari penggunaan inhibitor merupakan tujuan yang akan disampaikan di sini. Karakteristik dari bahan inbitor korosi dibahas untuk menjelaskan perbedaan di antara berbagai inhibitor yang telah dikenal. Senyawa organik heterosiklik diketahui memiliki sifat penghambatan yang baik terhadap korosi. Akan tetapi senyawanya beracun, mahal, dan tidak aman bagi lingkungan. Dengan demikian investigasi difokuskan pada perkembangan yang terjadi secara alami, untuk mendapatkan inhibitor korosi yang bersifat ecofriendly atau ramah lingkungan. Ekstrak dari beberapa tanaman telah dilaporkan sebagai penghambat untuk berbagai korosi di berbagai belahan dunia termasuk Indonesia [4].

\section{PROSEDUR PENGASAMAN}

Di antara asam, asam klorida $(\mathrm{HCl})$ adalah salah satu yang paling banyak digunakan beberapa industri sebagai untuk menghilangkan oksida yang tidak diinginkan seperti film dan produk korosi dari permukaan baja [1,9]. Bahan-bahan kasar, terutama baja ringan digunakan dalam media asam di sebagian besar industri termasuk eksplorasi minyak dan gas serta berbagai aktifitas industri lainnya [14]. Asam klorida banyak digunakan dalam pengawetan, perataan permukaan dan stimulasi sumur minyak untuk meningkatkan aliran minyak dan gas ${ }^{[8,14]}$. Karena sifat korosifnya yang tinggi, asam dapat menyebabkan kerusakan pada komponen sistem ${ }^{[1]}$.

Bahan-bahan berbasiskan baja akan mengalami kerusakan jika bahan tersebut bersentuhan dengan zat yang bersifat agresif terutama asam. Asam seperti $\mathrm{HCl}$ dapat diinjeksikan ke dalam pipa melalui stimulasi, pemindahan skala atau operasi pemulihan minyak yang disempurnakan. Asam lainnya dapat dihasilkan dalam proses melalui pemecahan $\mathrm{CO}_{2}$ dan $\mathrm{H}_{2} \mathrm{~S}$ atau limbah dari beberapa bakteri. Air sendiri merupakan penyebab korosi pada ladang minyak karena air berfungsi sebagai medium yang merubah zat non korosif $\left(\mathrm{CO}_{2}\right.$ dan $\mathrm{H}_{2} \mathrm{~S}$ ) larut menjadi asam yang bersifat korosif [6].

Asam fosfat $\left(\mathrm{H}_{3} \mathrm{PO}_{4}\right)$ adalah produk kimia utama yang memiliki banyak kegunaan penting terutama dalam produksi pupuk. Selain itu asam fosfat adalah asam sedikit kuat yang banyak digunakan dalam proses perawatan permukaan baja seperti pemolesan kimia dan elektrolitik atau etsa, pewarnaan kimia, pengangkatan film oksida, dan pembersihan permukaan. Meskipun $\mathrm{H}_{3} \mathrm{PO}_{4}$ adalah asam sedikit kuat tetapi menunjukkan korosi yang kuat pada baja. Dengan demikian sangat dibutuhkan zat untuk melindungi bahan baja yang digunakan dalam larutan $\mathrm{H}_{3} \mathrm{PO}_{4}$. Dibandingkan dengan inhibisi korosi pada media $\mathrm{HCl}$ dan $\mathrm{H}_{2} \mathrm{SO}_{4}$, perhatian terhadap medium $\mathrm{H}_{3} \mathrm{PO}_{4}$ dan senyawa yang dapat menghalangi korosinya masih rendah [12,13].

\section{MATERIAL UNTUK KONSTRUKSI DAN PROSES INHIBISI KOROSI}

Berbagai material digunakan sebagai bahan konstruksi dan dalam hal ini dipakai sebagai bahan penelitian meliputi baja ringan (MS) $[3,5,6,9,13,14,10,15-17]$, baja gulung roll (CRS) [17], baja karbon [1,12], baja pipa API 5L X42 [8], baja X80, dan J55 [6].

Senyawa lain yang telah diteliti di antaranya Fe(II) fosfat, Fe(III) asetilasetonat, Fe (II) asetilasetonat, Co(asetilasetonat)2, $\mathrm{Cu}$ (asetilaeetonat)2, $\quad \mathrm{Mn}$ (asetilacetonat)2, $\mathrm{Zn}$ (asetilasetonat)2 dari Merck, $\mathrm{NaCl}$ [21,17], $\mathrm{HCl}$, $\mathrm{H}_{2} \mathrm{SO}_{4}[1-9,13-16,18-25]$, trikloroasetat $\left(\mathrm{Cl}_{3} \mathrm{CCOOH}\right){ }^{[17]}$, Zn klorida, 2-mercaptobenzoxzol [20], sodium glukonat and surfaktan kationik [21], metionin dan ion iodida ${ }^{[22,23]}$.

Inhibitor yang digunakan antara lain; ekstrak Lecaniodiscus cupaniodes $^{[1]}$, ekstrak daun Dendrocalamus brandisii (DBLE) [17], ekstrak Tagetes erecta atau bunga marigold (TEE) dan luten [16], ekstrak etanol daun Acalypha torta (EAL) [9], ekstrak kulit Cucumis sativus (CSP) [25], ekstrak Andrographis paniculata, ekstrak biji Strychnos nuxvomica, ekstrak buah Moringa oleifera, ekstrak batang bacopa [13], tanin dari 
Rhizophora racemosa[14], ekstrak biji Griffonia simplicifolia (SEGS) [6], ekstrak Kola nitida (KN) [10], purpald (4-amino-3-hidrazino-5-merkapto1,2,4-triazol (AHMT)) [12], ekstrak Pandanus tectorius[1], ekstrak kulit bawang merah [2], gum arabic (GA) [8], ekstrak henna (Lawsonia inermis) [7], ekstrak daun Cryptostegia grandiflora[5], ekstrak Ervatamia coronaria ${ }^{[9]}$, ekstrak daun Cucurbita maxima (LCM) [16], ekstrak daun Toona sinensis (TSLE) [18], ekstrak daun fragmen osmanthus (OFLE) [11], ekstrak Argemone mexicana ${ }^{[4]}$ ekstrak asam daun Hibiscus sabdariffa ${ }^{[19]}$.

\section{INHIBITOR KOROSI}

Penghambat atau inhibitor korosi banyak digunakan di industri untuk menghalangi korosi logam, karena inhibitor mampu memperlambat dan bahkan hampir menghilangkan proses korosif yang terjadi dalam transportasi, produksi dan penyimpanan minyak dan turunannya. Mayoritas inhibitor yang digunakan dalam industri dalam korosi asam adalah senyawa organik yang mengandung atom nitrogen, oksigen dan sulfur. Inhibitor yang mempunyai dua atau lebih ikatan rangkap juga mengambil bagian penting dalam memfasilitasi adsorpsi senyawa ini ke permukaan logam, karena ikatan dapat terbentuk antara pasangan elektron dan atau awan elektron atom donor dan permukaan logam sehingga mengurangi serangan zat korosif pada media asam. Dengan demikian inhibitor digunakan untuk menurunkan laju korosi logam dalam asam. Jadi inhibitor tersebut adalah zat yang digunakan untuk menghentikan atau memperlambat proses korosi [2].

Penggunaan inhibitor merupakan salah satu metode yang paling praktis untuk perlindungan terhadap korosi terutama dalam larutan asam yang dapat mencegah pengrusakan logam dan penggunaan asam yang tidak diharapkan. Senyawa organik dan anorganik yang berbeda dipelajari sebagai penghambat untuk melindungi logam dari serangan korosi. Kemampuan suatu senyawa untuk dijadikan sebagai penghambat tergantung pada kemampuannya untuk membentuk film penghalang yang kuat dan mempunyai sifat adsorpsi pada permukaan logam. Biasanya, senyawa organik memberikan pengaruh yang signifikan terhadap luas daerah teradsorpsi pada permukaan logam. Kemampuan teradsorpsi yang tinggi dari inhibitor menyebabkannya dapat digunakan sebagai inhibitor korosi yang efektif. Efisiensi inhibitor korosi organik ini terkait dengan adanya fungsi kutub dari atom sulfur, oksigen atau nitrogen dalam molekul, senyawa heterosiklik dan elektron orbital p. Fungsi kutub biasanya dianggap sebagai pusat reaksi pembentukan proses adsorpsi [1].

Efek berbahaya yang diketahui dari kebanyakan penghambat organik sintetis, dan peraturan lingkungan yang ketat memberikan tekanan kepada para peneliti untuk fokus memenuhi kebutuhan dan mengembangkan produk alami yang murah dan ramah lingkungan sebagai inhibitor korosi [1]. Penggunaan senyawa sintetis ini dalam medium menyebabkan perlu adanya tambahan waktu dan biaya untuk pengolahan lebih lanjut dari sistem pembuangan pengolahan sehingga tidak berperan sebagai efluen. Pemeliharaan sistem diperlukan untuk memastikan tingkat unsur atau senyawa yang diizinkan dan dapat dikendalikan berdasarkan undang-undang lingkungan. Teknologi tepat guna dalam pengolahan air limbah yang efisien merupakan salah satu faktor penentu perizinan lingkungan dan commissioning pabrik petrokimia. Keberlanjutan lingkungan dan meningkatnya biaya inhibitor sintetis menjadi motivasi pencarian alternatif yang lebih murah dan ramah lingkungan seperti inhibitor korosi yang berasal dari produk alami. Selain itu, pengolahan makanan menghasilkan produk sampingan dan limbah yang kaya akan senyawa biokomponen dapat yang menjadi sumber antioksidan alami yang tersedia dengan murah dan mudah ${ }^{[2]}$.

\section{Inhibitor Sintetis}

Senyawa organik yang mengandung atom nitrogen, oksigen dan sulfur merupakan inhibitor korosi dalam media asam yang paling dikenal. Sampai saat ini beberapa jenis senyawa 
organik telah digunakan sebagai inhibitor korosi baja dalam larutan $\mathrm{H}_{3} \mathrm{PO}_{4}$, seperti bahan polimer, senyawa N-heterosiklik, garam amonium n-alkil-kuartener, turunan thiosemikarbazida, propargil alkohol, polivinilpirolidon dan polietilenimin, tiourea,senyawa tiofen dan kompleks rutenium-ligan. Penggunaan turunan triazol dalam inhibisi korosi baja di medium $\mathrm{H}_{3} \mathrm{PO}_{4}$ yang ditemukan sedikit atau hanya beberapa riset yang telah dilakukan. Akan tetapi turunan triazol pada inhibisi korosi besi atau baja dalam media $\mathrm{HCl}$ dan $\mathrm{H}_{2} \mathrm{SO}_{4}$ lebih menarik perhatian karena kinerjanya sebagai inhibitor korosi yang sangat baik ${ }^{[12]}$.

Namun, sebagian besar inhibitor yang dipakai selama ini adalah senyawa sintetis, yang mahal dan dapat menyebabkan masalah yang serius terhadap lingkungan [6,13,14]. Pengembangan dan penerapan inhibitor korosi difokuskan pada zat yang lebih murah dan ramah lingkungan. Ekstrak tanaman kemudian muncul sebagai inhibitor efektif korosi karena biaya rendah, biodegradabilitas tinggi, ketersediaan melimpah dan sifat tidak beracun [11]. Dalam perkembangan selanjutnya turunan triazol digunakan sebagai inhibitor korosi pada media asam. Karakteristik inhibisi korosi dari purpad, yaitu 4-amino-3-hidrazino-5-merkapto-1,2,4triazole (AHMT) dipelajari pada baja karbon dalam medium $\mathrm{H}_{3} \mathrm{PO}_{4} 2 \mathrm{M}$. Pilihan kepada purpad didasarkan atas sifat inhibisinya yang baik terhadap korosi baja ringan dengan larutan $\mathrm{H}_{2} \mathrm{SO}_{4} 2,5 \mathrm{M}{ }^{[12]}$.

Kompleks asetilasetonat logam banyak digunakan sebagai katalis reaksi kimia misal oksidatif dehidrogenasi (ODH) etana dan epoksidasi geraniol serta sebagai penstabil atau prekursor dalam proses sol-gel. Senyawa kompleks tersebut digunakan dalam lapisan polimer sebagai penstabil dalam reaksi pembentukan silang, katalis proses pengeringan dan zat penguat. Sangat sedikit penelitian yang telah dilakukan untuk mempelajari sifat anti korosi dari kompleks asetilasetonat logam ini. Penelitian proses inhibisi korosi melalui presipitasi Fe (II) fosfat dan Fe (III) fosfat dengan adanya Fe (III) asetilasetonat dan Fe (II) asetilasetonat. Dalam hal ini baja ringan direndam dalam larutan mengandung fosfat. Palladium asetilasetonat disarankan sebagai inhibitor korosi yang efektif untuk reaktor nuklir berpendingin air, paladium asetilasetonat terurai dan menyimpan paladium pada permukaan oksida $[3,17]$.

Kompleks serium, terbium, praseodimium asetilasetonat digunakan untuk merancang pigmen perlindungan korosi non-toksik. Interaksi kompleks logam transisi dengan baja ringan sangat dipengaruhi oleh potensial elektroda standarnya, reaktivitas dan sifat ligan yang dapat menstabilkan kompleks logam. Potensial elektroda standar dari kation divalen mengikuti orde: $\mathrm{Cu}(\mathrm{II}) / \mathrm{Cu}(+0.34 \mathrm{~V})>\mathrm{Co}$ $(\mathrm{II}) / \mathrm{Co}(-0.277 \mathrm{~V})>\mathrm{Fe}(\mathrm{II}) / \mathrm{Fe}(-0.44 \mathrm{~V})>\mathrm{Zn}$ $(\mathrm{II}) / \mathrm{Zn} \quad(-0,76 \mathrm{~V})>\mathrm{Mn} \quad(\mathrm{II}) / \mathrm{Mn} \quad(-1.18 \mathrm{~V})$. Kehilangan spesi $\mathrm{Cu}$ (II) dan Co (II) pada permukaan baja ringan dimungkinkan karena potensial elektrodanya besar dibandingkan dengan Fe (II). Akan tetapi ligan bermuatan negatif seperti nitro, tiosianat, oksalat, glikoksin dan asetilasetonat dapat menstabilkan keadaan oksidasi yang lebih tinggi. Dengan demikian reduksi $\mathrm{Cu}$ (II) dan Co (II) pada permukaan baja dapat dipengaruhi oleh ligan yang mengelilinginya [17].

\section{Inhibitor Alami}

Berbagai studi menunjukkan bahwa ekstrak tumbuhan obat umumnya kaya akan flavonoid, alkaloid, polifenol, dan lain-lain. Senyawa organik alami dari ekstrak tumbuhan memiliki beberapa heteroatom dalam struktur molekulnya sehingga dapat berperan sebagai inhibitor [9]. Penggunaan inhibitor adalah salah satu cara terbaik untuk melindungi logam dari korosi yang disebabkan oleh larutan asam. Dengan demikian, ekstrak tumbuhan menjadi penting sebagai sumber penghambat korosi efektif yang ramah lingkungan, ekonomis, mudah tersedia dan terbarukan. Berbagai upaya telah dilakukan dan diarahkan pada perumusan inhibitor korosi yang aman ditinjau dari berbagai aspek [5]. 
Senyawa organik alami ini disintesis atau diambil dari ramuan aromatik, rempah-rempah dan tanaman obat. Ekstrak tanaman dipandang sebagai sumber senyawa kimia sintesis yang sangat kaya yang dapat diekstraksi dengan prosedur sederhana dengan biaya rendah dan bersifat biodegradebel. Bidang penelitian senyawa organik alam sebagai inhibitor sangat penting karena selain ramah lingkungan dan dapat diterima secara ekologis, produk tanaman tidak mahal, tersedia dan sumber bahan terbarukan [1]. Undang-undang lingkungan yang ketat dan meningkatnya kesadaran ekologi di berbagai kalangan telah menyebabkan peningkatan pengembangan green alternative untuk mengurangi tingkat korosi [13]. Acalypha torta merupakan tumbuhan yang termasuk keluarga euphorbiaceae, memiliki beragam khasiat obat, dan digunakan untuk pengobatan malaria, rematik, perut mulas, dermatitis, dan eksim infantil[9].

\section{Inhibitor Sinergetik}

Bentuk film protektif karena adsorpsi molekul inhibitor ini yang membatasi pergerakan ion jauh dari permukaan korosi atau konsumsi elektron. Namun dalam banyak kasus, keduanya bertindak baik sebagai inhibitor anodik maupun katodik. Sedangkan penggunaan tripolifosfat atau asam fosfat dan/atau campuran dari keduanya dengan inhibitor lain tidak dapat menghambat korosi baja ringan terutama di industri petrokimia. Dalam kasus tersebut, efek sinergis ternyata meningkatkan efisiensi inhibisi korosi, implikasi biaya yang lebih rendah dari penggunaan salah satu dari keduanya merupakan alasan utama pemakaian inhibitor secara bersamaan ${ }^{[14]}$.

Dalam penelitian lain dipelajari dampak penambahan kation seng dan 2merkaptobenzoksazol (MBO) terhadap proteksi korosi dari lapisan sol-gel silan pada baja ringan. Efektivitas inhibitor organik dan anorganik pada korosi baja ringan dalam larutan $\mathrm{NaCl}$ terbukti terkait dengan pembentukan film permukaan. Dengan menggunakan data elektrokimia serta hasil analisis permukaan, sinergisme inhibisi semakin tajam jika persentase $\mathrm{mol} \mathrm{ZnCl}_{2}$ dan MBO berjumlah sama yang ditambahkan ke larutan $\mathrm{NaCl}$. Sedangkan, data elektrokimia menunjukkan kinerja lapisan film dipermukaan semakin memberikan pengaruh yang besar jika digunakan kombinasi inhibitor [20].

Pengaruh sodium glukonat (SG), setiltrimetilammoniumbromida (CTAB) dan campurannya pada korosi baja galvanisasi dalam larutan $\mathrm{NaCl} 3,0 \%$ diteliti menggunakan metoda elektrokimia yang digabungkan dengan pemindaian mikroskop elektron (SEM). Pengukuran polarisasi menunjukkan bahwa SG, CTAB dan campurannya bertindak sebagai inhibitor tipe katodik. Efek sinergis ditemukan antara SG dan CTAB. Efisiensi inhibisi campuran keduanya mencapai $94 \%$ pada konsentrasi SG 10-3 M dan CTAB 2,74 × 10-5 M. Selain itu, efisiensi inhibisi ini sangat meningkat dengan waktu dan suhu peremdaman. Analisis sinar-X SEMdan energi (EDX) menunjukkan bahwa homogenitas permukaan meningkat dengan penambahan campuran ${ }^{[21]}$.

Lapisan baja karbon rendah nanokristalin (SNCLCS) yang ditempatkan pada substrat baja karbon rendah oleh percikan magnetron dan baja curah (BLCS) diteliti sifat korosinya dalam larutan $\mathrm{H}_{2} \mathrm{SO}_{4}$ 0,5 $\mathrm{M}$ dengan metode EIS dan polarisasi. Efek penghambatan korosi aditif metionin dan KI secara sinergis juga dipelajari. Hasilnya menunjukkan bahwa kedua spesimen baja tersebut mengalami korosi aktif tanpa transisi menuju passivasi pada rentang potensial yang dipelajari. Metionin menghambat korosi kedua spesimen dengan efisiensi inhibisi yang sebanding dan ion iodida secara sinergis akan meningkatkan efisiensi inhibisi [22].

Efek inhibisi sinergis ekstrak daun Dendrocalmus sinicus Chia et JL Sun (DSCLE)/senyawa utamanya (rutin dan orientin) dan ion iodida (I-) pada korosi baja canai dingin (CRS) dalam larutan $\mathrm{H}_{3} \mathrm{PO}_{4}$ 0,1 M dan suhu $25-60^{\circ} \mathrm{C}$ dipelajari dengan metode kehilangan berat, polarisasi potentiodinamik, metode spektroskopi impedansi elektrokimia 
(EIS) dan metode perhitungan kimia kuantum. DSCLE dan dua senyawa utama berperan sebagai inhibitor moderat dengan urutan efisiensi inhibisi DSCLE > rutin > orientin. Namun, penggabungan mereka dengan Isecara signifikan meningkatkan kinerja inhibisi, dan menghasilkan efek penghambatan sinergis yang kuat ${ }^{[23]}$.

\section{METODE PENGUKURAN KOROSI}

Proses korosi dan penentuan efisiensi inhibisi korosi berbagai baja dalam beberapa larutan atau media korosif oleh inhibitor organik, ekstrak tanaman dan ion-ion serta efek sinergetik inhibitor menggunakan metode kehilangan berat, polarisasi potensiodinamik dan spektroskopi impedansi elektrokimia (EIS).

\section{Kehilangan Berat}

Tingkat korosi dalam berbagai laporan ditentukan menggunakan metode pengukuran kehilangan berat sebagai prosedur standar. Metode ini menghitung perbedaan antara berat baja yang hilang selama perendaman dalam medium korosif dan dalam medium korosif yang mengandung ekstrak ataupun senyawa kimia tertentu $[1,2,4,9,10,12,14-18,24]$.

\section{Polarisasi Potensiodinamik}

Metode polarisasi potensiodinamik merupakan suatu metode yang digunakan untuk menentukan sifat korosi logam dan baja berdasarkan hubungan potensial dan arus anodik atau katodik. Jika material berinteraksi dengan larutan yang bersifat korosif maka pada permukaan logam dapat terjadi reaksi reduksi ataupun oksidasi secara bersamaan. Korosi logam terjadi ketika terdapat arus anodik yang besarnya sama dengan arus katodik. Hal ini disebabkan adanya perbedaan potensial antara logam dengan larutan elektrolit sebagai medium logam tersebut. Perbedaan potensial yang dihasilkan merupakan potensial korosi, Ecorr $[1-12,14-16,18,24]$.

\section{Spektroskopi Impendansi Elektrokimia}

Metode spektroskopi impendansi elektrokimia yang lebih dikenal dengan EIS merupakan suatu teknik eksperimen elektrokimia yang memiliki peranan khusus dalam penelitian korosi. Pada prinsipnya EIS dapat menentukan sejumlah parameter yang berkaitan dengan kinetika elektrokimia seperti tahanan polarisasi, tahanan larutan, dan kapasitansi lapis rangkap listrik.

Besarnya arus (Icorr) berbanding lurus dengan laju korosi berdasarkan persamaan Stern-Geary yang memberikan hubungan langsung antara arus korosi dan tahanan arus searah yang melewati antarmuka logam dan larutan elektrolit. Arus listrik yang mengalir melalui antarmuka dipandang sebagai bagian dari reaksi elektrokimia yaitu proses transfer muatan dalam pembentukan antarmuka yang bermuatan. Kinetika elektrokimia korosi pada logam dapat dikarakterisasi dengan menentukan tiga parameter yakni densitas hantaran, potensial korosi dan slop Tafel katodik. Interaksi antara antarmuka dan larutan akan menimbulkan arus tertentu. Berdasarkan ekstrapolasi Tafel, dapat diketahui dominasi reaksi yang terjadi antara anodik dan katodik [1-7,9-12,16-17, 24].

\section{Metode Teoritis}

Simulasi dinamika molekuler (MD) dilakukan dengan program Discover di perangkat lunak Material Studio 4.1 dari Accelrys Inc. Berdasarkan penelitian penggunaan MD tentang adsorpsi inhibitor pada permukaan baja, dapat terjadi interaksi yang kuat antara inhibitor organik dan permukaan $\mathrm{Fe}$ (001) dengan ukuran tertentu. Sementara itu, flavonoid utama pada ekstrak daun bambu terdiri dari rutin, orientin, isovientin dan vientin dan untuk dapat digunakan dalam metode MD diopmalkan dengan teori fungsi kepadatan muatan. Hasil perhitungan teoritis menunjukkan rutin, orientin, vientin dan isovientin sebagai flavonoid utama ekstrak bambu memiliki struktur skeleton molekuler yang serupa. Hal ini menyatakan bahwa rangkaian flavonoid dapat dianggap sebagai kontributor potensial untuk menghambat produk korosi pada besi [17]. 
Parameter aktivasi yang mengatur adsorpsi menunjukkan bahwa inhibitor secara fisik teradsorbsi melalui perhitungan kimia kuantum. Dengan menghitung parameter struktur seperti energi orbital molekul HOMO (orbital molekuler yang paling tinggi diduduki) dan LUMO (orbital molekul kosong yang tidak dihuni elektron), dan momen dipol dapat diketahui kelayakan tinggi dari adsorpsi lutein molekul dan terprotonasi, komponen utama ekstrak Tagetes erecta (TEE) pada permukaan baja ringan (MS). Pemodelan molekuler dilakukan untuk mengkorelasikan struktur komponen utama (lutein) TEE dengan efektivitas inhibisi korosi MS dalam asam sulfat menggunakan teori DFT ${ }^{[16]}$.

Jika struktur molekul dari unsur penyusun inhibitor diketahui secara pasti, struktur dan reaktivitas elektronik mereka serta sifat interaksi mereka dengan permukaan logam dapat dipastikan secara teoretis dengan menggunakan perhitungan kimia kuantum berbasis fungsi fungsional (DFT). Pendekatan ini semakin dapat diterima karena memberikan wawasan mekanika untuk memperhitungkan kemampuan ekstrak biomassa dalam menghambat korosi logam. Hasil eksperimental dan komputasi digabungkan pada analisis penggunaan ekstrak etanol biji Kola nitida (ekstrak KN) untuk meminimalkan korosi baja ringan dengan asam klorida. Pendekatan ini melibatkan karakterisasi awal ekstrak untuk mengidentifikasi konstituen organik, penilaian eksperimental terhadap kinerja inhibisi korosi ekstrak $\mathrm{KN}$ dan pemodelan komputasi struktur elektronik dan energi adsorpsi dari unsur penyusun ekstrak KN [10].

Parameter kimia kuantum juga dihitung pada inhibitor ekstrak daun fragmen osmanthus (OFLE), yang dapat menjelaskan secara teoritis dan logis gejala adsorpsi dan penghambatan OFLE pada baja karbon. Hasil perhitungan kimia kuantum dengan memodelkan struktur adsorpsi dari senyawa kimia asam askorbat, asam galat, flavonoid dan kariofilen untuk mengetahui sifat interaksi senyawa-senyawa tersebut dengan baja karbon, sekaligus kontribusinya terhadap efek inhibisi [11].

\section{KARAKTERISASI PRODUK KOROSI}

Permukaan baja yang belum mengalami korosi dan telah terkorosi serta yang mendapatkan inhibisi dari berbagai inhibitor dianalis dengan menggunakan metode SEM dan teknik mikroskop gaya atom (AFM) [9,11,17,18]. SEM merupakan salah satu jenis mikroskop elektron yang memakai berkas elektron untuk menggambarkan keadaan permukaan material yang dianalisis. Prinsip dari SEM adalah dengan menggambarkan permukaan benda atau material dengan berkas elektron yang dipantulkan dengan energi tinggi. Permukaan material yang disinari atau terkena berkas elektron akan memantulkan kembali berkas elektron yang dikenal sebagai berkas elektron sekunder ke segala arah $[6,7,11,18]$.

SEM memiliki resolusi yang jauh lebih tinggi dibandingkan dengan mikroskop optik. Panjang gelombang de Broglie yang dimiliki elektron lebih pendek dari pada gelombang optik akan menyebabkan resolusi SEM menjadi tinggi, karena makin kecil panjang gelombang yang digunakan maka makin tinggi resolusi sebuah mikroskop. Peralatan SEM dilengkapi dengan detektor dispersi energi (EDX) sehingga dapat digunakan untuk mengetahui komposisi unsur penyusun bahan yang dianalisis [9].

Penentuan gugus fungsi dan perubahan setelah proses korosi dan inhibisi berlangsung dapat dilakukan dengan menggunakan peralatan spektrum infra merah Fourier transform infrared(FTIR). Prinsip dasar FTIR berhubungan dengan spektrum infra merah suatu molekul adalah hasil transisi antara tingkat energi getaran yang berlainan. Gerakan getaran sebuah molekul menyerupai gerakan suatu bola yang dipasang pada pegas yakni osilasi harmoni. Jika senyawa organik dikenai sinar infra-merah yang mempunyai frekuensi tertentu (bilangan gelombang 500-4000 $\mathrm{cm}^{-1}$ ), menyebabkan beberapa frekuensi tersebut akan diserap oleh senyawa organik tersebut $[11,18]$. 


\section{MEKANISME INHIBISI KOROSI}

Struktur molekul yang mengandung atom oksigen, sulfur dan nitrogen serta senyawa heterosiklik dan elektron $\pi$ dipunyainya merupakan karakteristik yang sangat penting dari suatu senyawa dengan efek inhibisi korosi. Gugus fungsi biasanya dianggap sebagai pusat reaksi dalam pembentukan proses adsorpsi suatu senyawa pada permukaan logam. Mekanisme adsorpsi molekul organik pada permukaan logam dapat terjadi melalui empat cara (a) daya tarik elektrostatik antara molekul bermuatan dan logam bermuatan, (b) interaksi pasangan elektron tak bermuatan dalam molekul dengan logam, (c) interaksi dari elektron- $\pi$ dengan logam dan (d) kombinasi dari cara (a) dan (c) $)^{[5,17]}$.

Mekanisme inhibisi korosi oleh senyawa organik tergantung pada struktur dan gugus fungsi yang dimiliki senyawa organik tersebut, sifat logam yang mengalami korosi dan medium agresif yang berkontak dengan logam. Inhibisi korosi baja ringan dikaitkan dengan adsorpsi inhibitor pada antarmuka baja ringan dan medium korosif. Tingkat adsorpsi inhibitor ditentukan oleh sifat baja ringan dan kondisi permukaannya dan jenis adsorpsi inhibitor. Adsorpsi pada permukaan baja ringan terjadi melalui interaksi pusat aktif atau gugus yang dimiliki inhibitor dan bergantung pada rapat muatannya (Gambar 4) ${ }^{[3]}$.

Dalam medium korosif seperti asam klorida, baja ringan dapat mengalami oksidasi dan menghasilkan $\mathrm{Fe}^{2+}$. Ion besi(II) ini dapat berinteraksi dengan inhibitor yang berada dalam medium korosif melalui pembentukan senyawa kompleks. Senyawa lawson yang terdapat dalam ekstrak inai membentuk kompleks dengan $\mathrm{Fe}^{2+}$ (Gambar 5) dan akan teradsorpsi secara kimia di permukaan baja ringan ${ }^{[7]}$.

Inhibitor organik banyak dipakai untuk menghambat korosi di berbagai industri karena dapat berfungsi efektif pada rentang suhu suhu yang lebar, kompatibilitas dengan bahan yang dilindungi cukup dan kelarutan yang baik serta toksisitas yang relatif rendah. Mekanisme inhibisi oleh senyawa organik didasarkan pada adsorpsi oleh permukaan dengan membentuk lapisan pasif yang berfungsi sebagai pelindung melalui pemindahan molekul air dari permukaan logam dan sekaligus melindungi dari proses korosi. Mekanisme ini tidak sepenuhnya adsorpsi fisik atau kimia saja. Akan tetapi adsorpsi dipengaruhi oleh struktur kimia inhibitor organik, muatan dan kondisi permukaan, distribusi muatan dalam molekul serta media korosif (Tabel 1). Adsorpsi fisik didasarkan pada interaksi elektrostatik antara permukaan logam bermuatan dan molekul inhibitor bermuatan. Adsorpsi kimia dihubungkan dengan interaksi donor-akseptor antara pasangan elektron bebas dan orbital $d$ logam yang kosong dengan tingkat energi rendah [26].

Inhibitor korosi organik yang efektif harus mengandung heteroatom (nitrogen, oksigen, sulfur dan fosfor) dengan pasangan elektron bebas dan dalam kerangka strukturnya terdapat elektron $\pi$ (cincin aromatik dan beberapa ikatan) yang mampu berinteraksi dengan orbital bebas logam yakni baja ringan. Berbagai faktor tersebut saling mendukung dalam proses adsorpsi inhibitor pada permukaan.

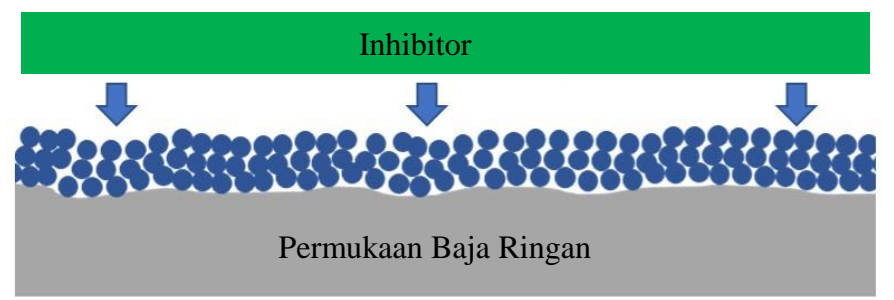

Gambar 4. Ilustrasi penutupan permukaan baja ringan oleh inhibitor dan sekaligus melindungi dari serangan korosi 


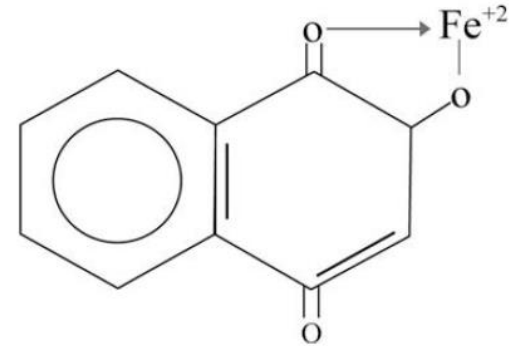

Gambar 5. Struktur senyawa kompleks lawson dan ion besi(II)

Penggunaan basa Schiff 3-(5-metoksi-2hidroksibenzilidinamino)-2-(-5-metoksi-

2hidroksifenil)-2,3-dihidroquinazolin sebagai inhibitor korosi memungkinkan terbentuknya gaya tarik elektrostatik, ikatan pasangan elektron bebas pada heteroatom dan ikatan elektron $\pi$ dari cincin dan ikatan rangkap inhibitor ke permukaan baja ringan (Gambar 6). Peningkatan konsentrasi inhibitor akan meningkatkan jumlah molekul inhibitor yang berinteraksi dengan permukaan sehingga lapisan pasif yang terbentuk akan semakin luas. Dengan demikian efisiensi inhibisi korosi akan meningkat pula ${ }^{[27]}$

Ekstrak alami yang diambil dari berbagai sumber tumbuhan mempunyai struktur yang dapat menunjang proses adsorpsi pada permukaan baja ringan dan baja karbon. Efisiensi inhibisi yang tinggi dari ekstrak famili papaveraceae Argemone mexicana terutama karena ekstrak bijinya mengandung alkaloid erisotrin, erisodin, eritralin, hiponin, eritroidin dan erbidin. Ekstrak dan minyak dari semak dan tumbuhan liar yang memiliki alkaloid semacam itu dapat menjadi penghambat yang lebih baik karena variasi kandungan kimia dan ketersediaan yang tinggi [4]. Lecaniodiscus cupaniodes adalah spesimen tanaman keluarga sapindaceae, tanaman tropis yang tersebar luas di Afrika dan Asia. Kandungan kimia Lecaniodiscus cupaniodes adalah $2,37 \%$ alkaloid, $0,336 \%$ saponin, $0,012 \%$ tanin, $0,008 \%$ fenol dan $0,002 \%$ antrakuinon. Lecaniodiscus cupaniodes telah terbukti menjadi senyawa yang manjur untuk menghilangkan malaria. Dari kandungan kimia tumbuhan liar ini dapat diprediksi ekstraknya akan mampu menghambat korosi karena senyawa kandungannya mempunyai syarat untuk bertindak sebagai inhibitor korosi.

Berbagai ekstrak dari bagian tumbuhan yang terbuang dengan sumber daya berlimpah mempunyai potensi tinggi menghambat korosi baja ringan dalam berbagai media korosif. Bagian tumbuhan tersebut antara lain daun bambu, bunga marigold, daun inai, biji Kola nitida $[1,4,10]$.
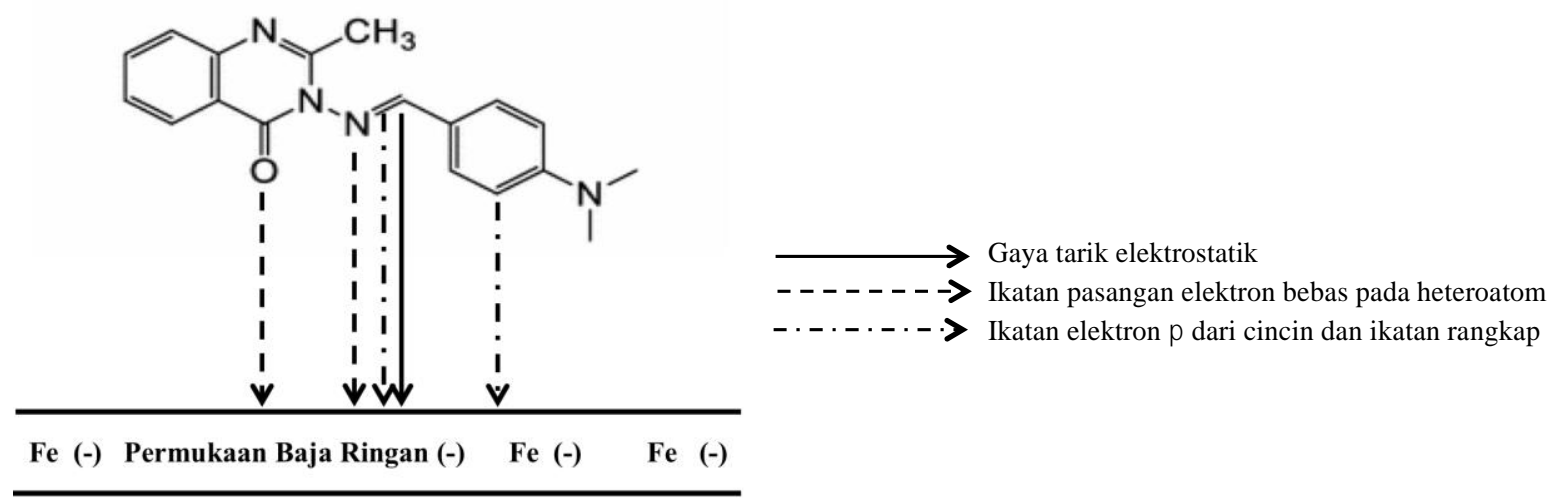

Gambar 6. Diagram skematis mekanisme adsorpsi basa Schiff pada permukaan baja ringan. 
Tabel 1. Sifat-sifat dari green inhibitor korosi baja dalam berbagai medium korosif

\begin{tabular}{|c|c|c|c|c|c|}
\hline Inhibitor & Medium & $\begin{array}{l}\text { Tipe } \\
\text { inhibitor }\end{array}$ & $\begin{array}{l}\text { Efisiensi } \\
\text { inhibisi, \% }\end{array}$ & Mekanisme & Reff. \\
\hline Ekstrak P. tectorius & $\mathrm{H}_{2} \mathrm{SO}_{4}$ & Campuran & 88,02 & Fisisorpsi & 1 \\
\hline Komp.Co(acac) 2 & $\mathrm{NaCl}$ & Presipitasi & 80,00 & & 2 \\
\hline Komp.Cu(acac) 2 & $\mathrm{NaCl}$ & Presipitasi & 83,00 & $\begin{array}{l}\text { Kompleks } \\
\text { logam pada }\end{array}$ & 2 \\
\hline Komp.Mn(acac)2 & $\mathrm{NaCl}$ & Presipitasi & 81,00 & permukaan baja & 2 \\
\hline Komp.Zn(acac)2 & $\mathrm{NaCl}$ & Presipitasi & 81,00 & ringan & 2 \\
\hline Ekstrak A. Mexicana & $\mathrm{HCl}$ & Campuran & 92,50 & Adsorpsi & 3 \\
\hline $\begin{array}{l}\text { Ekstrak C. } \\
\text { grandiflora }\end{array}$ & $\mathrm{H}_{2} \mathrm{SO}_{4}$ & Campuran & 87,54 & Fisisorpsi & 4 \\
\hline Ekstrak G. simplicifolic & $\mathrm{HCl}$ & Campuran & 91,73 & Fisisorpsi & 5 \\
\hline Ekstrak henna & $\mathrm{HCl}$ & Campuran & 92,06 & Aksi oksigen & 6 \\
\hline Ekstrak G. Arabic & $\mathrm{HCl}$ & Campuran & 92,00 & Fisisorpsi & 7 \\
\hline $\begin{array}{l}\text { Ekstrak kulit } \\
\text { bawang }\end{array}$ & $\mathrm{HCl}$ & Campuran & 94,00 & Kimisorpsi & 8 \\
\hline Ekstrak A. torta & $\mathrm{HCl}$ & Campuran & 91,00 & Fisisorpsi & 9 \\
\hline Ekstrak K. nitida & $\mathrm{HCl}$ & Campuran & 79,10 & Film protektif & 10 \\
\hline Ekstrak O. fragran & $\mathrm{HCl}$ & Campuran & 96,60 & Fisisorpsi & 11 \\
\hline Purpald & $\mathrm{H}_{3} \mathrm{PO}_{4}$ & Campuran & 96,80 & $\begin{array}{l}\text { Fisisorpsi dan } \\
\text { ads. } \\
\text { elektrostatik }\end{array}$ & 12 \\
\hline $\begin{array}{l}\text { Ekstrak } A \text {. } \\
\text { paniculata }\end{array}$ & $\mathrm{HCl}$ & Campuran & 98,00 & Film protektif & 13 \\
\hline Tanin $R$. racemosa & $\mathrm{HCl}$ & - & 72,00 & Multilayer ads. & 14 \\
\hline $\begin{array}{l}\text { Ekstrak } L . \\
\text { cupaniodes }\end{array}$ & $\mathrm{HCl}$ & - & 90,00 & - & 15 \\
\hline Ekstrak T. erecta & $\mathrm{H}_{2} \mathrm{SO}_{4}$ & Campuran & 98,07 & Fisisorpsi & 16 \\
\hline Ekstrak D. brandisii & $\mathrm{Cl}_{3} \mathrm{CCOOH}$ & Campuran & 95,00 & Ads. inhibitor & 17 \\
\hline Ekstrak T. sinensis & $\mathrm{HCl}$ & - & 92,35 & Fisisorpsi & 18 \\
\hline \multirow[t]{2}{*}{ Ekstrak H. sabdariffa } & $\mathrm{HCl}$ & - & 60,00 & - & 19 \\
\hline & $\mathrm{H}_{2} \mathrm{SO}_{4}$ & - & 90,00 & - & \\
\hline
\end{tabular}

Molekul organik yang memiliki kemampuan untuk teradsorpsi pada antarmuka logam dan larutannya dapat berfungsi dengan menonaktifkan bagian aktif korosi atau pemblokiran geometrik permukaan yang terbuka ataupun kedua mekanisme itu terjadi secara bersamaan. Menariknya, jika struktur molekul dari unsur penyusun inhibitor diketahui secara pasti, struktur dan reaktivitas elektronik serta sifat interaksi senyawa itu dengan permukaan logam dapat dipastikan secara teoritis dengan menggunakan perhitungan kimia kuantum berbasis DFT. Pendekatan ini semakin dapat diterima dengan menganalisis karakteristik adsorpsi beberapa 
senyawa organik yang ada dalam ekstrakArgemone Mexicana ${ }^{[16-18]}$

\section{KESIMPULAN}

Inhibisi korosi baja di berbagai media korosif perlu dihambat dengan penggunaan inhibitor korosi yang sesuai. Sejumlah senyawa dan ekstrak beberapa bagian tumbuhan digunakan sebagai inhibitor korosi baja dalam larutan korosif. Berbagai senyawa organik mempunyai potensi untuk menghambat korosi baja. Senyawa organik yang mempunyai kandungan unsur N, S dan O dalam kerangka strukturnya sangat efektif sebagai inhibitor korosi yang sangat baik. Akan tetapi umumnya senyawa organik tersebut memiliki efek toksik yang tidak diinginkan dan juga tergolong mahal. Dengan demikian, ekstrak tumbuhan dan produk alami telah digunakan sebagai inhibitor korosi yang dapat diterima secara lingkungan, tersedia dalam jumlah besar, murah, dan memiliki molekul efektif dengan efisiensi inhibisi yang sangat tinggi dan dampak lingkungan rendah. Inhibitor green korosi terbukti efektif dari perspektif ekologi dan lingkungan serta dapat memainkan peran penting menggantikan inhibitor lain yang bersifat toksik. Hal lain yang lebih menakjubkan dan memberikan harapan yang besar adalah efisiensi anti korosi inhibitor korosi ini sama atau bahkan lebih efektif daripada inhibitor sintetis. Ekstrak tumbuhan dan senyawa kompleks yang diteliti dalam berbagai larutan korosif pada umumnya mempunyai efisiensi yang tinggi. Tipe inhibitor green korosi dari berbagai ekstrak tumbuhan dapat diketahui secara akurat dan mekanisme inhibisinya dapat ditentukan dengan baik.

\section{DAFTAR PUSTAKA}

1. Al-Turkustani, A. M., Thermodynamic, chemical and electrochemical investigation of Pandanus tectorius extract as corrosion inhibitor for steel in sulfuric acid solutions, Eur. J. Chem., 4(3): 303-310 (2013).

2. Ferreira, K.C.R., Cordeiro, R.F.B., Nunes, J.C., Orofino, H., Magalhães, A., Torres,
A.G.,\& D'Elia, E., Corrosion inhibition of carbon steel in $\mathrm{HCl}$ solution by aqueous brown onion peel extract, Int. J. Electrochem. Sci., 11: 406 - 418 (2016).

3. Mahdavian, M., \& Attar, M. M., Electrochemical behaviour of some transition metal acetylacetonate complexes as corrosion inhibitors for mild steel. Corros. Sci., 51(2): 409-414 (2009).

4. Ji, G., Shukla, S.K., Dwivedi, P., Sundaram, S., Prakash, \& R., Inhibitive effect of Argemone mexicana plant extract on acid corrosion of mild steel. Ind. Eng. Chem. Res., 50(21): 11954-11959 (2011).

5. Prabakaran, M., Kim, S-H., Hemapriya, V., \& Chung, I.M., Evaluation of polyphenol composition and anticorrosion properties of Cryptostegia grandiflora plant extract on mild steel in acidic medium, J Ind Eng Chem, 37: 47-56 (2016).

6. Ituen, E., Akaranta, O., James, A., \& Sun, S., Green and sustainable local biomaterials for oil field chemicals: Griffonia simplicifolia extract as steel corrosion inhibitor in hydrochloric acid, SMET, 11: 12-18 (2017).

7. Ostovari, A., Hoseinieh, S.M., Peikari, M., Shadizadeh, S.R., \& Hashemi, S.J., Corrosion inhibition of mild steel in $1 \mathrm{M}$ $\mathrm{HCl}$ solution by henna extract: A comparative study of the inhibition by henna and its constituents (lawsone, gallic acid, a-D-glucose and tannic acid), Corros. Sci., 51(9): 1935-1949 (2009).

8. Bentrah, M., Rahali, Y., \& Chala, A., Gum Arabic as an eco-friendly inhibitor for API 5L X42 pipeline steel in $\mathrm{HCl}$ medium, Corros. Sci., 82: 426-431 (2014).

9. Krishnegowda, P.M., Venkatesha, V.T., Krishnegowda, P.K.M., \& Shivayogiraju, S.B., Acalypha torta leaf extract as green corrosion inhibitor for mild steel in hydrochloric acid solution, J. Ind. Eng. Chem., 52(2): 722-728 (2013).

10. Oguzie, E.E., Njoku, D.I., Chidebere, M.A., Ogukwe, C.E., \& Onuoha, G.N., Characterization and experimental and computational assessment of Kola nitida 
extract for corrosion inhibiting efficacy, Ind. Eng. Chem. Res. 53(14): 5886-5894 (2014).

11. Li, L., Zhang, X., Lei, J., He, J., Zhang, S., \& Pan, F., Adsorption and corrosion inhibition of Osmanthus fragran leaves extract on carbon steel, Corros. Sci., 63: 82-90 (2012).

12. Zarrok, H., Zarrouk, A., Hammouti, B., Salghi, R., Jama, C., \& Bentiss, F., Corrosion control of carbon steel in phosphoric acid by purpald - Weight loss, electrochemical and XPS studies, Corros. Sci., 64: 243-252 (2012).

13. Singh, A., Ebenso, E.E.,\& Quraishi, M.A., Corrosion inhibition of carbon steel in $\mathrm{HCl}$ Solution by some plant extracts, International Journal of Corrosion. 2012: 120 (2012).

14. Oki, M., Charles, E., Alaka, C., \& Oki, T.K., Corrosion inhibition of mild steel in hydrochloric acid by tannins from Rhizophora racemosa, Mater. Sci. Appl., 2(6): 592-595 (2011).

15. Joseph, O.O., Fayomi, O.S.I., Joseph, O.O., \& Adenigba, O.A., Effect of Lecaniodiscus cupaniodes extract in corrosion inhibition of normalized and annealed mild steels in $0.5 \mathrm{M} \mathrm{HCl}$, Energy Procedia, 119: 845-851 (2017).

16. Mourya, P., Banerjee, S., \& Singh, M.M., Corrosion inhibition of mild steel in acidic solution by Tagetes erecta (Marigold flower) extract as a green inhibitor, Corros. Sci., 85: 352-363 (2014).

17. Li, X., Deng, S., Li, N., \& Xie, X., Inhibition effect of bamboo leaves extract on cold rolled steel in $\mathrm{Cl}_{3} \mathrm{CCOOH}$ solution, J. Mater. Res. Technol., 6(2):158170 (2017).

18. Emriadi, Santoni, A., \& Stiadi, Y., Adsorptive and thermodynamic properties of methanol extract of Toona sinensis leaves for the corrosion of mild steel in $\mathrm{HCl}$ medium, Der Pharma Chem., 8(18): 266-273 (2016).

19. Murthy, Z.V.P., \& Vijayaragavan, K., Mild steel corrosion inhibition by acid extract of leaves of Hibiscus sabdariffa as a green corrosion inhibitor and sorption behavior, Green Chem. Lett. Rev., 7(3): 209219 (2014).

20. Alinejad, S., Naderia, R., \& Mahdavian M., Effect of inhibition synergism of zinc chloride and 2-mercaptobenzoxzole on protective performance of an ecofriendly silane coating on mild steel, J. Ind. Eng. Chem., 48: 88-98 (2017).

21. Azaroual, M.A., El Harrak, E.F., Touir, R., Rochdi, A., \& Touhami, M. E., Synergistic corrosion protection for galvanized steel in $3.0 \% \mathrm{NaCl}$ solution by sodium gluconate and cationic surfactant, J. Mol. Liq., 220: 549-557 (2016).

22. Oguzie, E.E., Li, Y., \& Wang, F.H., Effect of surface nanocrystallization on corrosion and corrosion inhibition of low carbon steel: Synergistic effect of methionine and iodide ion, Electrochim. Acta, 52(24):6988-6996 (2007).

23. Li, X., Deng S., Fu H., \& Xi, X., Synergistic inhibition effects of bamboo leaf extract/major components and iodide ion on the corrosion of steel in $\mathrm{H}_{3} \mathrm{PO}_{4}$ solution, Corros. Sci., 78: 29-42 (2014).

24. Sethuraman, M.G., Aishwarya, V., Kamal, C., Jebakumar T., \& Edison I., Studies on ervatinine - The anticorrosive phytoconstituent of Ervatamia coronaria, Arab. J. Chem., 10(1): S522-S530 (2017).

25. Al-Senani, G.M., Corrosion inhibition of carbon steel in acidic chloride medium by Cucumis sativus (cucumber) peel extract, Int. J. Electrochem. Sci., 11: 291-302 (2016).

26. Brycki, B.E., Kowalczyk, I.H., Szulc, A., Kaczerewska, O., \& Pakiet, M., Organic Corrosion Inhibitors, (Ed: Aliofkhazraei, M), IntechOpen, 3-33 (2018).

27. Khan, G., Basirun, W.J., Kazi, S.W., Ahmed, P., Ahmed, S.M., Khan, G.M., \& Rehman, M.A., Electrochemical investigation on the corrosion inhibition of mild steel by quinazoline Schiff base compounds in hydrochloric acid solution, J. Colloid Interface Sci., 502: 134145 (2017). 